\section{No ice-sheet collapse}

SIR - Blankenship et al. ${ }^{1}$ present intriguing evidence for a subglacial volcano that supports the characterization of central West Antartica as a rift zone ${ }^{2}$. I believe it highly unlikely that a volcano (even many volcanoes), or the properties of the lithosphere that they may represent, would make the ice sheet vulnerable to collapse.

The possibility of unstable collapse is important because it carries the implication of a serious rise in sea level. Blankenship et al. write that a retreat of the downstream termini of the ice streams (grounding line) to a proposed boundary between hot and cold lithosphere, marked approximately by the volcano, "would almost certainly represent an unstable situation", because the buffering ice streams would be unable to migrate upstream past that boundary. I do not dispute the likely instability of that situation if it were to arise, but the authors place that boundary about two-thirds of the way from the present grounding line to the centre of the ice sheet. A grounding-line retreat of such magnitude would probably mean that an instability had already been triggered. Further, it could hardly occur without induced retreat of adjacent drainage systems through the downdraw process $^{3}$, which would in turn imply that much of the West Antarctic ice sheet had already spread into the ocean. With grounding lines then deep into the Byrd subglacial basin, instability would be virtually assured with or without migrated ice streams. Thus the authors' proposed collapse mechanism would come into play so late in West Antartic ice-sheet shrinkage as to be largely irrelevant. The important point with regard to ice-sheet collapse is the stability of the ice stream as it now exists, which has nothing to do with lithospheric boundaries.

More fundamentally, I question the conclusion of Blankenship et al. that "elevated geothermal flux provides an important control on the dynamics of the [West Antarctic ice sheet]". Certainly, elevated heat flow would enhance melting from the underside of the ice sheet. But the coexistence of enhanced melt and ice streams is not evidence of cause and effect. Ice streams and other fast-moving glaciers are a common phenomenon in ice sheets past ${ }^{4}$ and present $t^{5}$, including those on presumably cold Precambrian shields in East Antarctica and Canada. Few, if any, are associated with volcanism - ample water is provided by the heat of glacial sliding ${ }^{6}$, so elevated heat flux is not generally needed for fast glacier flow. Is there reason, then, to suppose that high heat flow is an important control on West
Antarctic ice streams? The authors cite no supporting evidence, nor has any such evidence been reported in extensive study of those ice streams over the past decade (see ref. 7 for a summary).

In summary, although the geophysical evidence for volcanism provides interesting support for active rifting in West Antarctica, it should not be taken as threatening an imminent collapse of the West Antarctic ice sheet, contrary to some press reports that have appeared.

\section{Charles Bentley}

1215 West Dayton Street,

Madison, Wisconsin 53706, USA

1. Blankenship, D. D. et al. Nature 361, 526-529(1993).
2. LeMasurier, W. E. Geol. Soc. Am. Abstr. Progm 10, 443 (1978)

(1978). The Last Great ice Sheets (eds Denton, G. H. \& Hughes, T.) 319-436 (Wiley-Interscience, 1981)

4. Clark, P. U. EOS 74, $310(1993)$

5. Bentley, C. R. J. geophys. Res. 92, 8843-8857 (1987).

6. Lingle, C. S. \& Brown, T. J. in Dynamics of the West

Antarcticlce Sheet (eds Van der Veen, C. J. \& Oerlemands, J.) 249-285 (Reidel, Dordrecht, 1987)

7. Alley, R. B. \& Whillans, I. M. Science 254, 959-963 (1991)

\section{Sequence data as evidence}

SIR - The debate ${ }^{1,2}$ concerning the proposed transmission of HIV to five patients of a dentist suffering from AIDS highlights the difficulties in establishing networks of HIV transmission from the analysis of viral nucleotide sequence data. The details of that particular case notwithstanding, we believe that there are issues that need to be addressed before HIV sequence data alone can be used to resolve such questions.

The first issue is the choice of region of the HIV genome which provides the best estimate of relatedness. Ou et al.$^{1}$, in their analysis of the Florida dentist case, used sequences from the $\mathrm{C} 2-\mathrm{V} 3$ region of the env gene. This region was considered to be suitable for tracing transmission networks because of the extensive variability in sequence and the large amount of homologous data already available. However, identical V3 loop sequences have been observed to evolve in epidemiologically unrelated patients ${ }^{3}$ (convergent evolution) and individuals in the late stages of the disease often possess more diverse sequences than those obtained from early in infection ${ }^{4,5}$. Such complex evolutionary patterns will hinder accurate determination of the probabilities of transmission.

In another investigation of HIV transmission to a Swedish rape victim, Albert et $a{ }^{6}{ }^{6}$ analysed a region of the more conserved pol gene. Although shared substitutions in this region may be given more weight because they are relatively rare, it is likely that there may not always be sufficient variability to resolve particularly close relationships. Finally, we have used a region of the gag gene, encompassing part of the p17 protein, to determine whether an HIV infected surgeon had transmitted the virus to a patient $^{7}$. This region has an intermediate level of variability and such sequences were found to duplicate known pathways of transmission between individuals in a detailed analysis of HIV evolution in Edinburgh (E. C. H. et al., manuscript in preparation).

A second issue concerns the method of analysis of the sequence data. The most obvious approach involves the inference of the phylogenetic relationships of the sequences in question. It is possible, however, that HIV evolves in ways incompatible with the assumptions made by many methods of phylogenetic analysis. An example is again provided by the observation of convergent evolution in the V3 loop ${ }^{3,8}$. Such reservations also apply to the 'signature' sequence analysis undertaken by $\mathrm{Ou}$ et al. ${ }^{1}$ because, like cladistic methods of phylogenetic inference, it implicitly assumes the independent and divergent evolution of the relevant aminoacid residues. Furthermore, in this type of investigation it is crucial that an estimate of uncertainty be assigned to tree topologies, such as that provided by bootstrap resampling. An alternative method is based on the comparison of the log likelihoods of tree topologies which depict competing transmission networks ${ }^{7}$. Whatever the approach taken, it is important to recognize that the probabilities which can be attached to different phylogenies are orders of magnitude lower than those which are used in DNA fingerprinting based on VNTR sequences.

We believe that close attention to the points raised here, together with more detailed studies of the nature of HIV sequence evolution within communities, are required before HIV nucleotide sequence data can be regarded as evidence which can be used uncorroborated in a legal context.

\section{Edward C. Holmes*}

Andrew J. Leigh Brown

Centre for HIV Research,

Division of Biological Sciences,

University of Edinburgh,

Edinburgh EH9 $3 \mathrm{JN}$, UK

Peter Simmonds

Department of Medical Microbiology,

University of Edinburgh, Medical School, Edinburgh EH8 9AG, UK

* Present address: Department of Zoology, University of Oxford, Oxford OX1 3PS, UK

1. Ou, C. Y. et al. Science 256, 1165-1171 (1992). . DeBry, R. W. et al. Nature 361, 291 (1993)

3. Zhang, L. Q. et al J. Virol 67, 3345-3356 (1993).

4. Zheng, Q. et al. Jirol 67,3345 - 3356 (1993). J. Virol. 66, 6547-6554(1992)

5. Schuitemaker, H. etal. J. Virol. 66, 1354-1360 (1992).

6. Albert, J., Wahiberg, J. \& Uhlén, M. Nature 361, 595-596 (1993).

7. Holmes, E. C. et al. J. infect. Dis. 167, 1411-1414 (1993)

8. Holmes, E. C. etal. Proc. natn. Acad. Sci. U.S.A. 89 ,

4835-4839(1992) 